\title{
Electricity Consumption Forecasting Using Adaptive Neuro-Fuzzy Inference System (ANFIS)
}

\author{
K. G. Tay ${ }^{1, *}$, Hassan Muwafaq ${ }^{1}$, W. K. Tiong ${ }^{2}$, Y. Y. Choy ${ }^{3}$ \\ ${ }^{1}$ Faculty of Electrical and Electronics Engineering, Universiti Tun Hussein Onn Malaysia, Malaysia \\ ${ }^{2}$ Faculty of Computer Science and Information, Universiti Malaysia Sarawak, Malaysia \\ ${ }^{3}$ Faculty of Applied Science and Technology, Universiti Tun Hussein Onn Malaysia, Malaysia
}

Received August 1, 2019; Revised October 9, 2019; Accepted December 12, 2019

Copyright $\bigcirc 2019$ by authors, all rights reserved. Authors agree that this article remains permanently open access under the terms of the Creative Commons Attribution License 4.0 International License

\begin{abstract}
Universiti Tun Hussein Onn Malaysia (UTHM) is a developing Malaysian Technical University. There is a great development of UTHM since its formation in 1993. Therefore, it is crucial to have accurate future electricity consumption forecasting for its future energy management and saving. Even though there are previous works of electricity consumption forecasting using Adaptive Neuro-Fuzzy Inference System (ANFIS), but most of their data are multivariate data. In this study, we have only univariate data of UTHM electricity consumption from January 2009 to December 2018 and wish to forecast 2019 consumption. The univariate data was converted to multivariate and ANFIS was chosen as it carries both advantages of Artificial Neural Network (ANN) and Fuzzy Inference System (FIS). ANFIS yields the MAPE between actual and predicted electricity consumption of $0.4002 \%$ which is relatively low if compared to previous works of UTHM electricity forecasting using time series model (11.14\%), and first-order fuzzy time series $(5.74 \%)$, and multiple linear regression $(10.62 \%)$.
\end{abstract}

Keywords ANN, FIS, ANFIS, Electricity Consumption, Forecasting, UTHM

\section{Introduction}

Overestimation of electricity demand will cause the wasting of resources as electricity cannot be stored, while underestimation will lead to higher operation cost [1]. Reliable and accurate prediction of electricity consumption is therefore vital for Utilities Company to plan for future power generation and distribution. Load forecasting can be classified into short-term load forecasting (STLF), medium-term load forecasting (MTLF) and long-term load forecasting (LTLF). STLF forecasts load from one day or one week at most, MTF forecasts load one day to several months while LTF predicts more than a year ahead [2]. STLF plays role for scheduling the generation and transmission of electricity, MTLF tries to plan the fuel purchases, whereas LTLF is aimed to develop the power supply and delivery system (generation units, transmission system, and distribution system) [3].

Universiti Tun Hussein Onn Malaysia (UTHM) is a developing Malaysian Technical university which is located in Johor state in south Peninsular Malaysia. UTHM has two campuses. The main campus is in Parit Raja, Batu Pahat, Johor, while another campus is in Pagoh, Johor.

UTHM electricity consumption forecasting has been forecasted by using time series models [4], first-order fuzzy time series [5] and multiple linear regression [6] with MAPE of $11.14 \%, 5.74 \%$ and $10.62 \%$ respectively. We believe the prediction accuracy of the studies [4-6] still can be improved by employing other techniques such as autoregressive integrated moving average (ARIMA) [7], seasonal ARIMA (SARIMA) [8], artificial neural network (ANN) [8-12], support vector machine (SVM) [12], Least-square SVM (LSSVM) [1], support vector regression [9], ANFIS[13-15], ARIMA-ANFIS [16] etc.

Research in [13] applied pre-processing to improve noisy and missing data. They then considered the time of day, the day of the week, the heating degree of the day (HDD) and cooling degree of the day (CDD) as ANFIS inputs, whereas historical electricity load was target and output was the forecasted load to predict STLF.

Mordjaoui [14] forecasted STL using half-hour weekly load data rearranged in multi-input single output by ANFIS. Their ANFIS input and output structures are shown in Figure 1 below: 


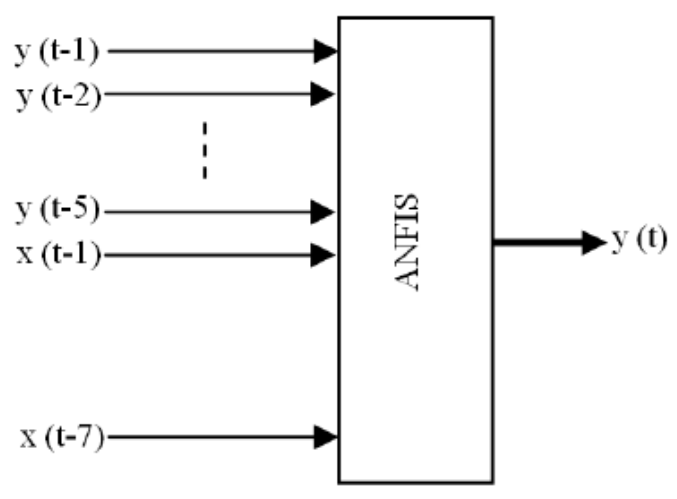

Figure 1. Input and output vectors to ANFIS [16]

However, it is not clearly written what is their variable $x(t)$.

Tiwari [15] forecasted electric load and price using input variables such as date, time, humidity and previous data sets taken from the various power corporation and obtained overall accuracy of $76.8 \%$.

Barak [16] employed population, GDP, export and import data to predict the annual energy consumption in Iran using 3 patterns of hybrid ARIMA-ANFIS model.

Most of the data structures of load forecasting using ANFIS are multivariate as seen in [13, 15-16], even data structure of research [16] is univariate but it is unclear how they made it multivariate. Our data only consists of monthly electricity consumption which is univariate similar to [16], but we will make it multivariate as shown in
Table 1. ANFIS was chosen to forecast UTHM future electricity consumption because it has the potential to capture the benefits of both ANN and FIS (Fuzzy Inference System) in a single framework.

\section{Adaptive Neuro-Fuzzy Inference System (ANFIS)}

ANFIS is a multilayered feedforward Artificial Neural Network (ANN) which applies NN learning algorithms and fuzzy reasoning. ANFIS uses Takagi-Sugeno fuzzy inference system (FIS) to map from input space to output space. Sugeno output membership functions are either linear or constant as given below:

Rule 1: If $\left(x_{1}\right.$ is $\left.A_{1}\right)$ and $\left(x_{2}\right.$ is $\left.B_{1}\right)$ then $\left(f_{1}=a_{1} x_{1}+\right.$ $\left.b_{1} x_{2}+c_{1}\right)$

Rule 2: If $\left(x_{1}\right.$ is $\left.A_{2}\right)$ and $\left(x_{2}\right.$ is $\left.B_{2}\right)$ then $\left(f_{2}=a_{2} x_{1}+\right.$ $\left.b_{2} x_{2}+c_{2}\right)$

Where $a_{i}, b_{i}, c_{i}$ for $i=1,2$ are coefficients and intercept of the linear function.

In another word, ANFIS is a combination of both ANN and FIS which has benefits of both ANN and FIS.

Figure 2 shows ANFIS architecture with two inputs and an output. The two inputs $x_{1}$ and $x_{2}$ will be fuzzified as fuzzy membership function in layer 1 as follows:

$$
\begin{aligned}
& O_{i}^{1}=\mu_{A_{i}}\left(x_{i}\right) \text { for } i=1,2 \\
& O_{i}^{1}=\mu_{B_{i-2}}\left(x_{i}\right) \text { for } i=3,4
\end{aligned}
$$

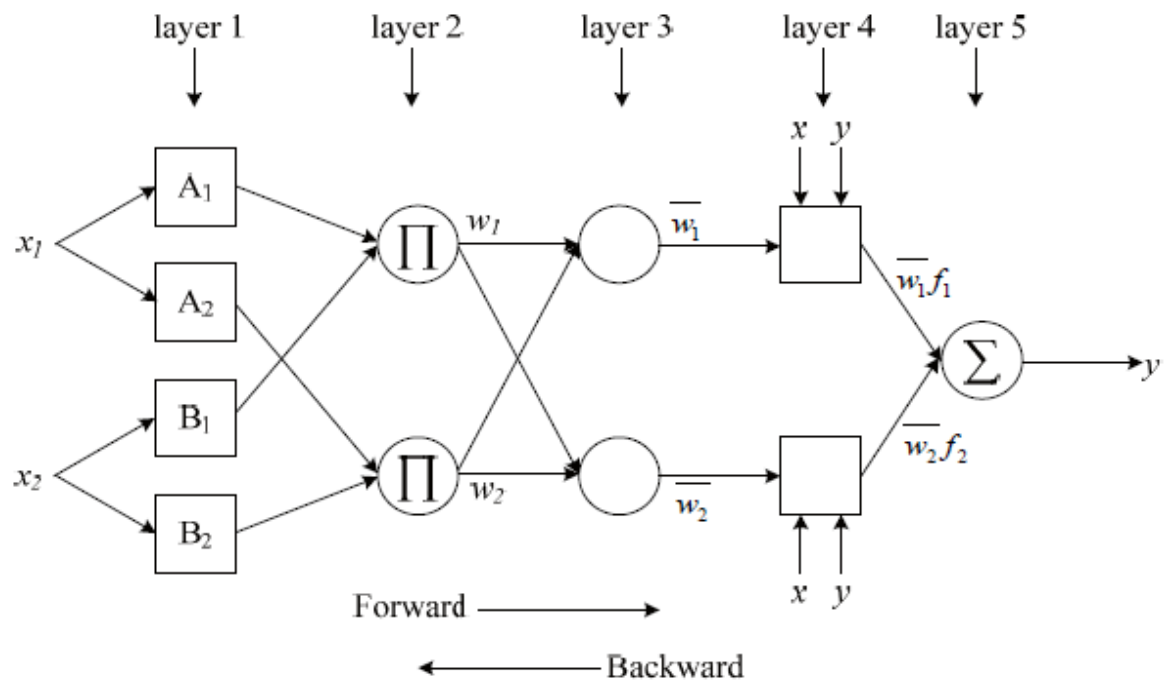

Figure 2. ANFIS architecture with two inputs and output [17] 
Where $O_{i}^{1}$ is the output of layer $1, \mu_{A}(x)$ and $\mu_{B}(x)$ are fuzzy membership functions.

Layer 2 is corresponding fuzzy rules as given below:

$$
O_{\mathrm{i}}^{2}=\omega_{i}=\mu_{A_{i}}\left(x_{i}\right) \mu_{B_{i}}\left(x_{i}\right) \text { for } i=1,2
$$

While layer 3 is normalization layer denoted as

$$
O_{i}^{3}=\bar{\omega}_{i}=\frac{\omega_{i}}{\omega_{1}+\omega_{2}} \text { for } i=1,2
$$

Lastly, layer 4 is defuzzification of the output membership function given as:

$$
O_{i}^{4}=\bar{\omega}_{i} f_{i}=\bar{\omega}_{i}\left(a_{i} x_{1}+b_{i} x_{1}+c_{i}\right) \text { for } i=1,2
$$

So, FIS is from fuzzification, fuzzy rules till defuzzification. The summation of all incoming signals will be passed to an activation function to be evaluated as an output.

$$
O_{i}^{5}=\sum_{i=1}^{2} \bar{\omega}_{i} f_{i}=\frac{\sum_{i=1}^{2} \omega_{i} f_{i}}{\omega_{1}+\omega_{2}} \text { for } i=1,2 \text { for } i=1,2
$$

\section{Material and Methods}

The monthly UTHM electricity consumption data from January 2009 to December 2018 was used to forecast UTHM monthly electricity consumption for the year 2019.

\subsection{Data Structure}

The 120 data was arranged in Table 1 such that the input is 108 rows by 12 columns, while the output is the last column of dimension 108 rows by 1 column starting from month 13 to month 120 as given in Table 1 . Here $M_{i}$ is the month $i$ of UTHM electricity consumption data from January 2009 to December 2018.

Table 1. Data structure

\begin{tabular}{|c|c|c|c|c|c|}
\hline \multicolumn{5}{|c|}{ Input } & Output \\
\hline$M_{1}$ & $M_{2}$ & $M_{3}$ & $\cdots$ & $M_{12}$ & $M_{13}$ \\
\hline$M_{2}$ & $M_{3}$ & $M_{4}$ & $\cdots$ & $M_{13}$ & $M_{14}$ \\
\hline$M_{3}$ & $M_{4}$ & $M_{5}$ & $\cdots$ & $M_{14}$ & $M_{15}$ \\
\hline$\vdots$ & $\vdots$ & $\vdots$ & $\cdots$ & $\vdots$ & $\vdots$ \\
\hline$M_{107}$ & $M_{108}$ & $M_{109}$ & $\cdots$ & $M_{118}$ & $M_{119}$ \\
\hline$M_{108}$ & $M_{109}$ & $M_{110}$ & $\cdots$ & $M_{119}$ & $M_{120}$ \\
\hline
\end{tabular}

\subsection{Methodology}

In this study, Neuro-Fuzzy Designer Apps as seen in Figure 3 from Matlab R2018b was used to do forecasting.

Basically, there are 4 stages in ANFIS. The first in data input, followed by FIS generation, training, and testing as seen in Figure 3.

The input data structure is given in Table 1 which has been save in Text (Tab delimited) format in Microfost Excel that will be loaded by clicking Load Data command button in Figure 3. The loaded data for training will be displayed in the graph in Figure 4

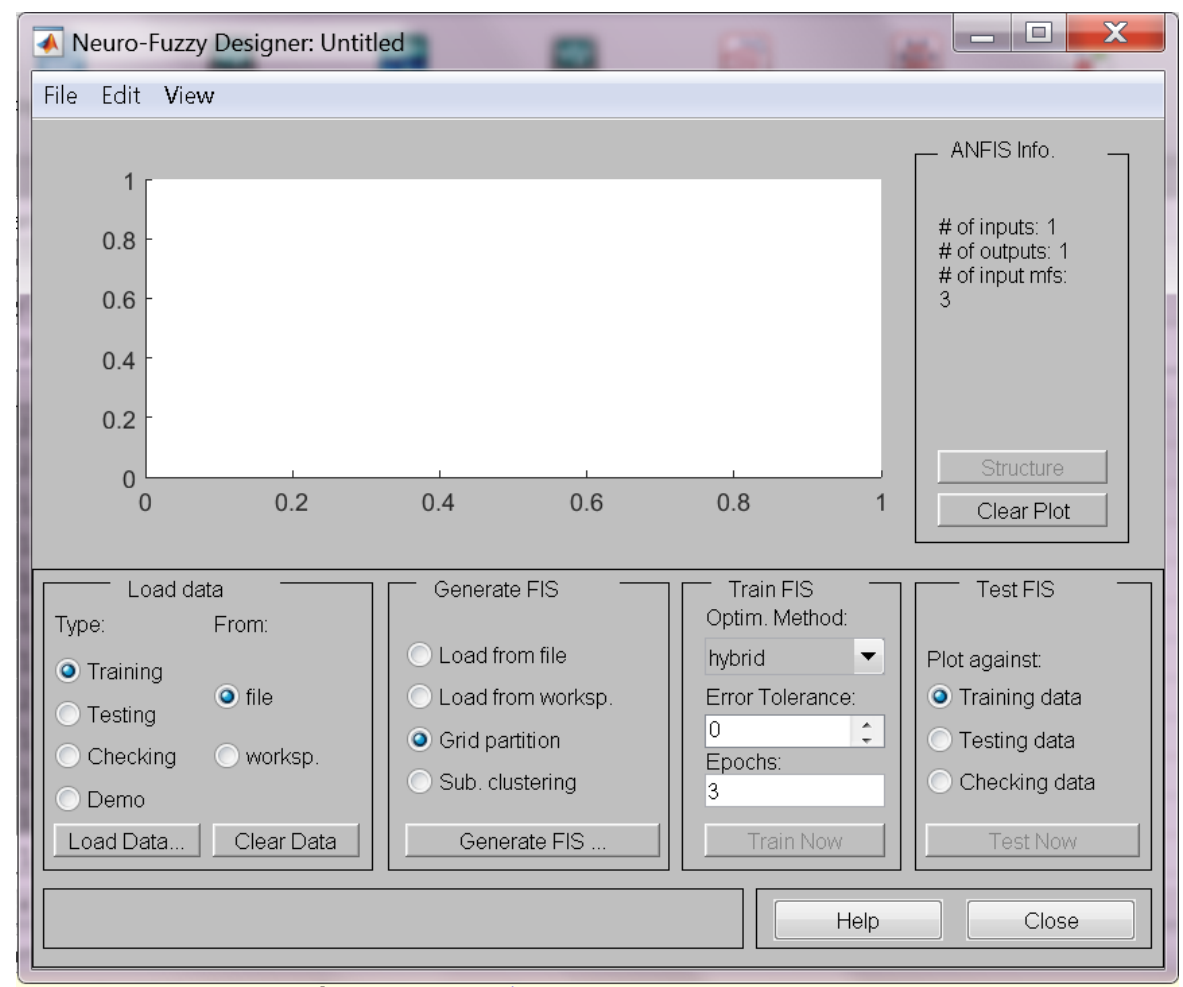

Figure 3. The initial window of ANFIS 


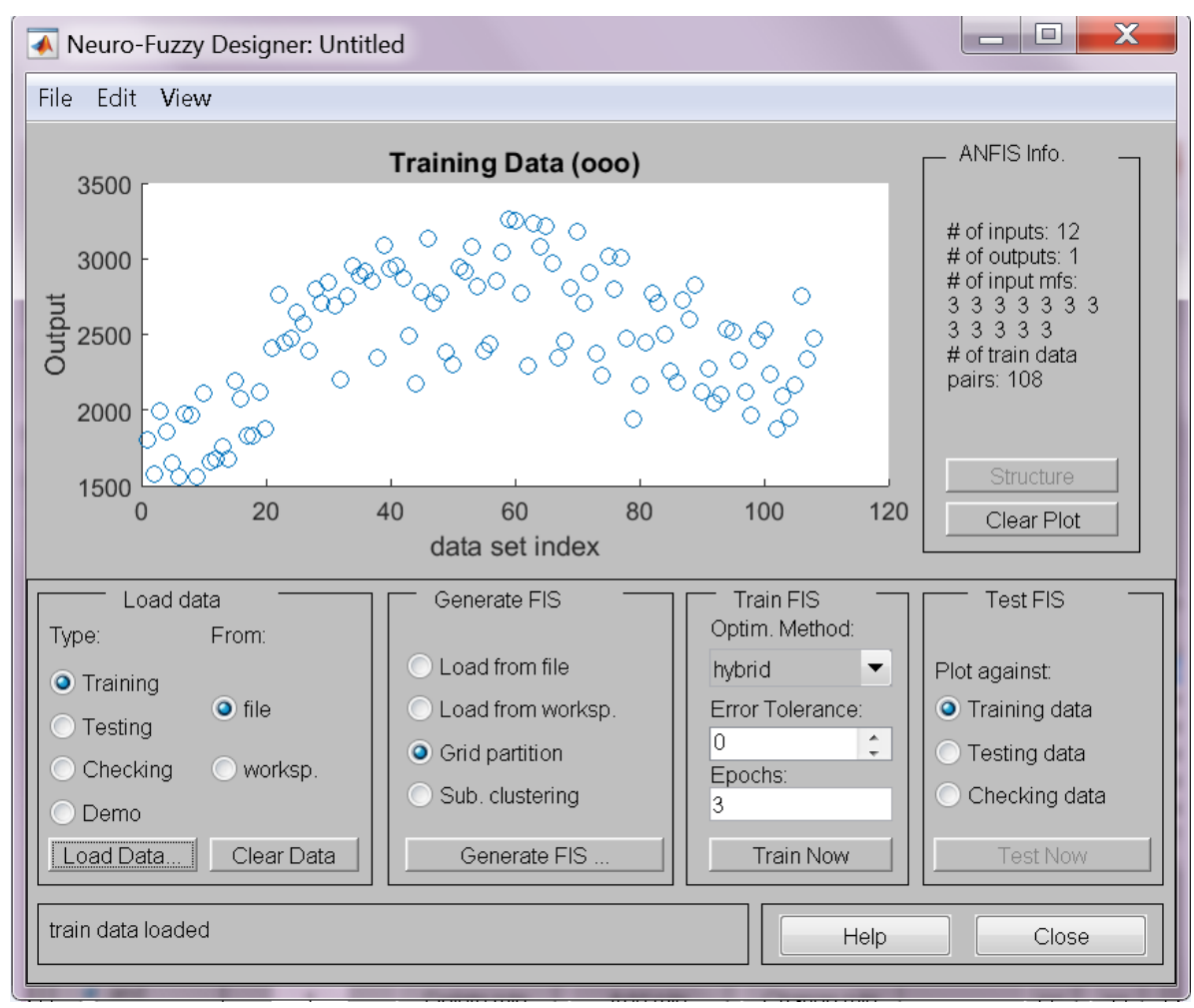

Figure 4. Data Loading

Later, Sub clustering option from Generate FIS portion followed by Generate FIS button will be used to generate FIS as it gives reasonable results and it is fast if compared to Grid partition option. The default parameter of Sub clustering will be used as seen in Figure 5.

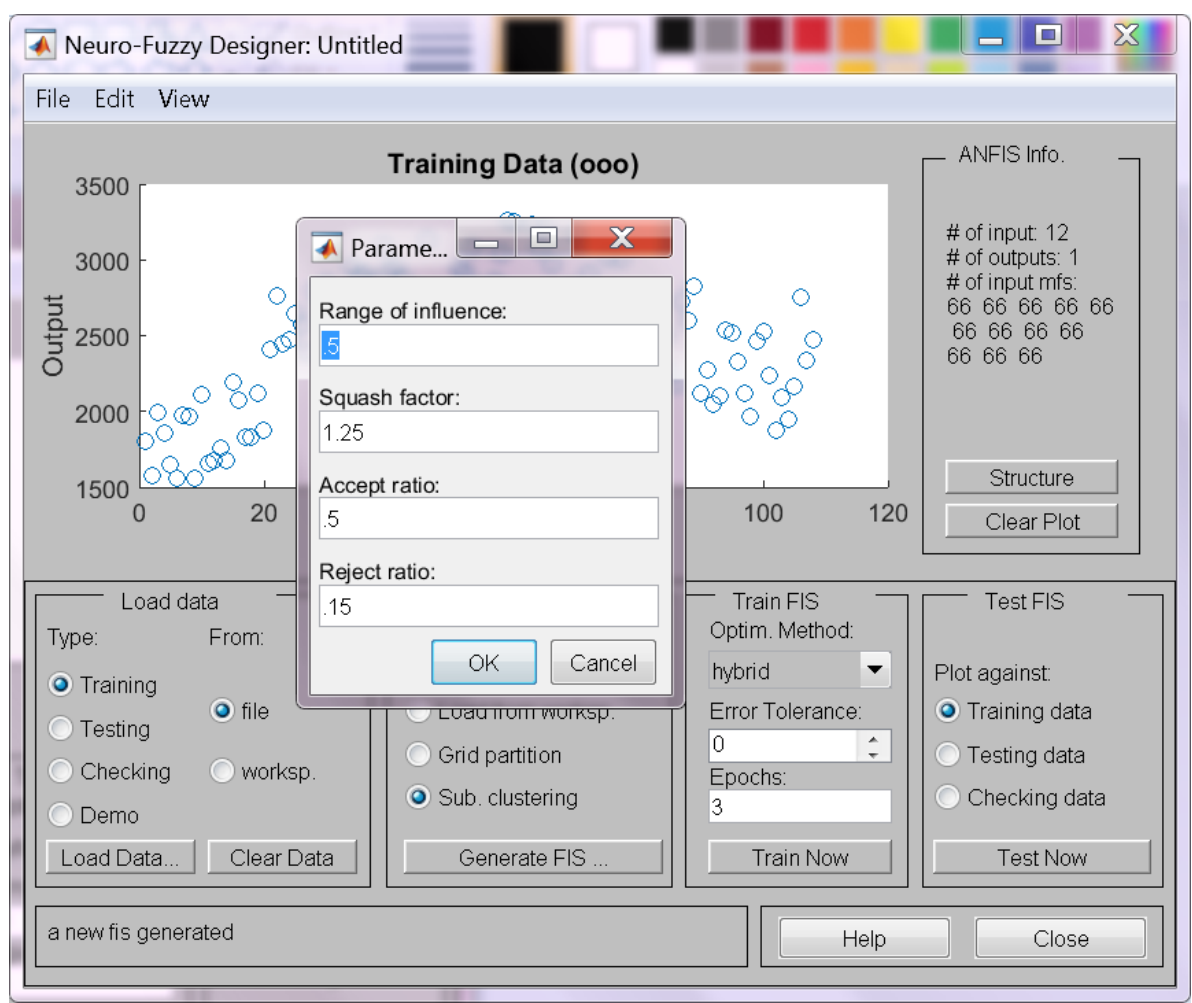

Figure 5. Sub clustering parameters 
Next, the OK button will be clicked followed by Train Now button. The FIS will be trained with a hybrid method with 0 error tolerance using 3 Epochs. Figure 6 depicts the root mean square (RMSE) for 3 Epochs used. The RMSE is 19.067665

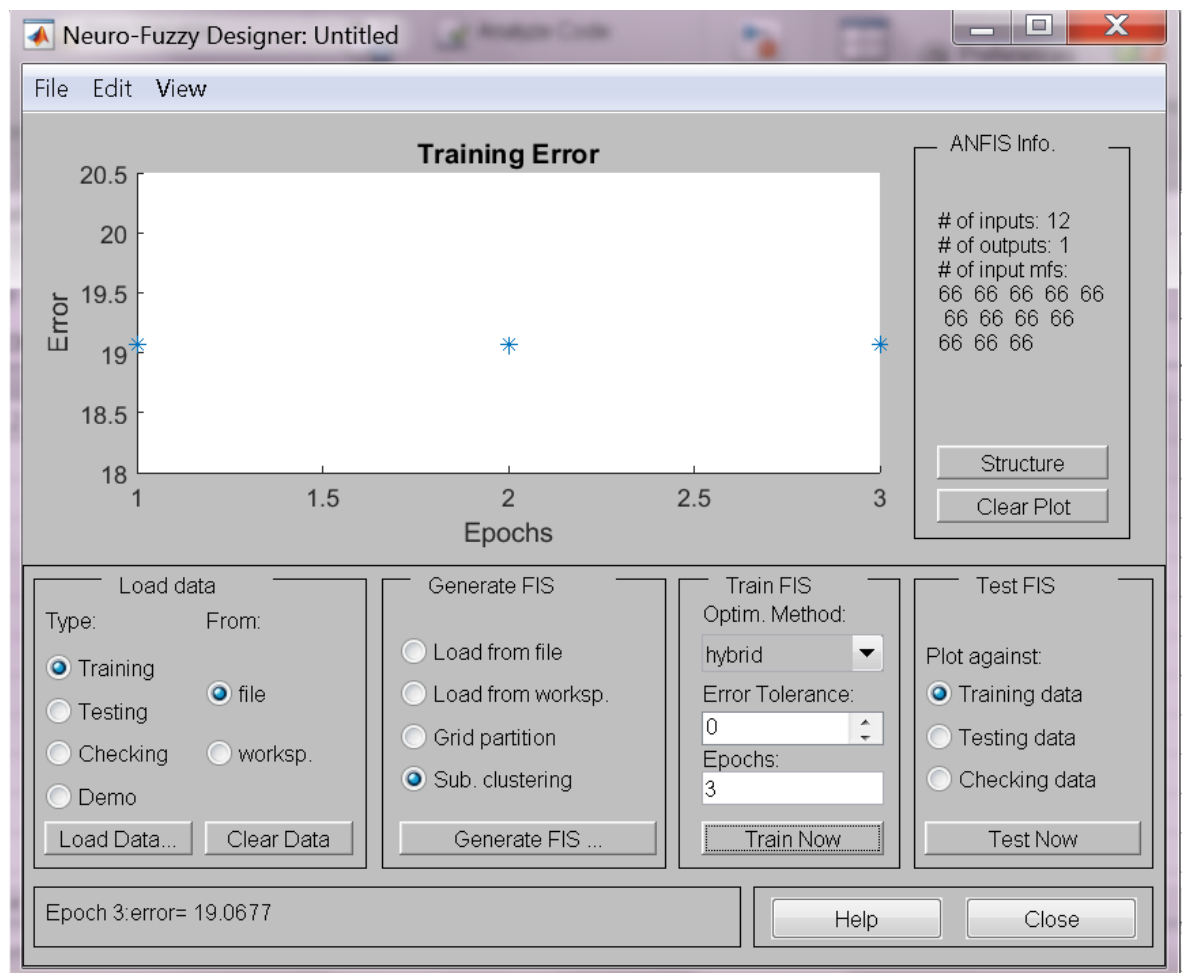

Figure 6. RMSE

Finally, once the Test Now button is clicked, Figure 7 will be obtained. It is noticed that blue color represents the training data, while red colour represents testing data, hence it can see that both training and testing data quite match.

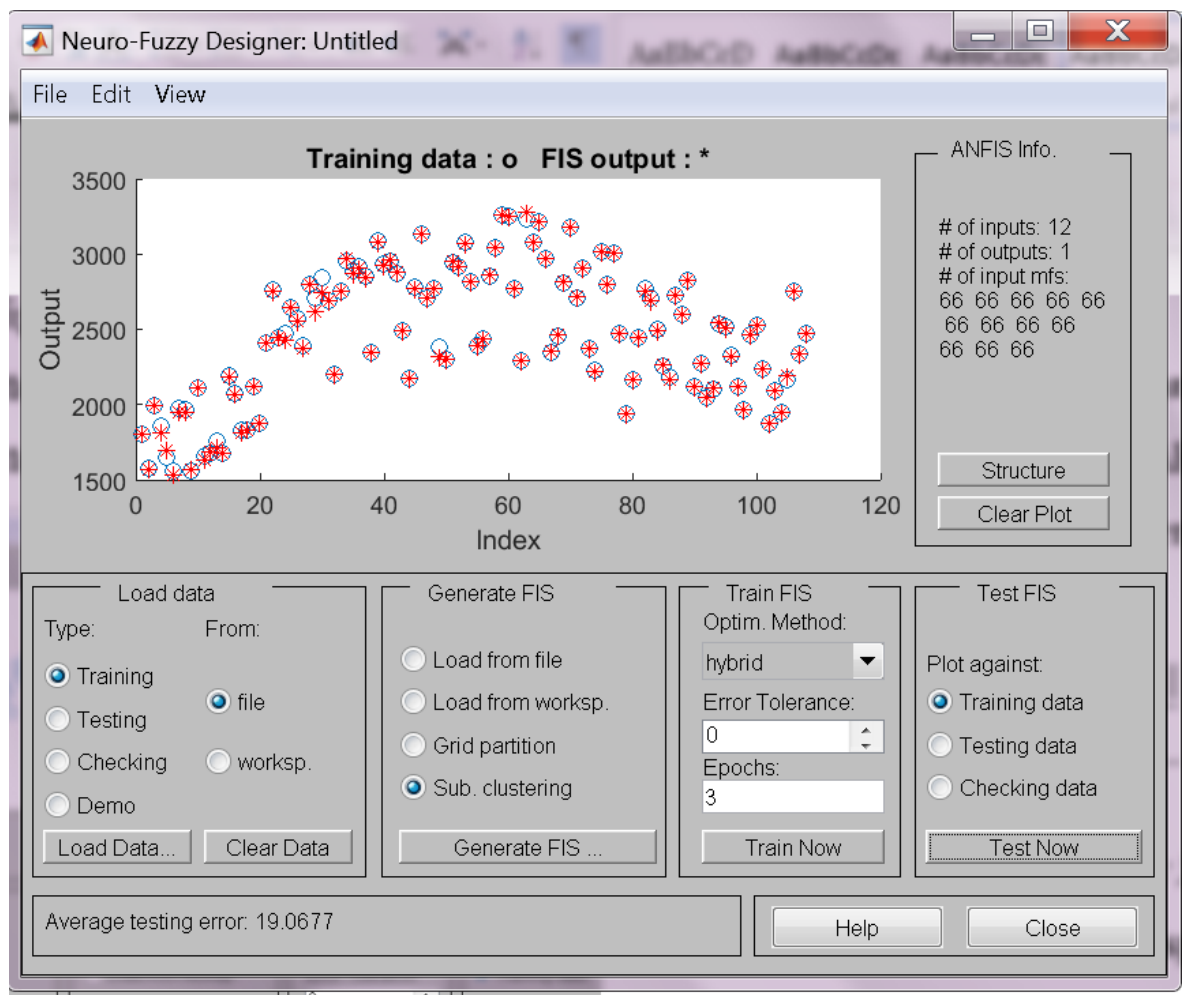

Figure 7. The plot of Training Data 


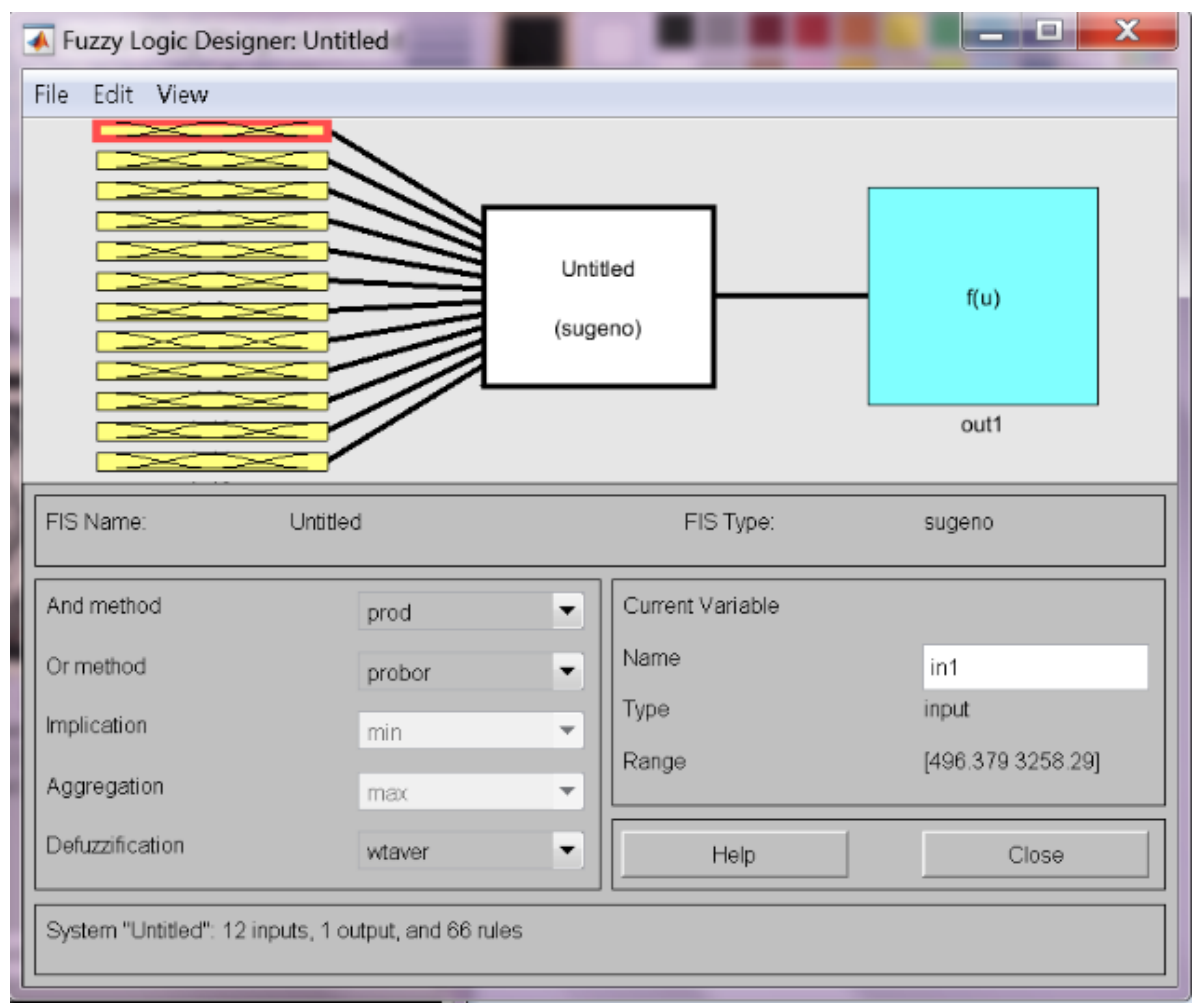

Figure 8. FIS properties

By clicking Edit menu, FIS properties option, we can see the ANFIS structure of this study consists of 12 inputs (the first 12 columns of Table 1) and 1 output (the last column of Table 1) as displayed in Figure 8. A Sugeno FIS is applied in ANFIS. It causes an output of either linear or constant value.

To obtain the structure of ANFIS in neural network (NN) form, the Structure button is clicked to obtain its NN structure as shown in Figure 9. The NN structure of this ANFIS reveals there are 12 inputs (the first twelve columns consists of 108 rows in Table 1) in the input layer and 1 output (the last column consists of 108 rows in Table 1). Each input neuron is fuzzified with Gaussian (refer Figure 10) membership function (first hidden layer) and its associated Fuzzy rule (second hidden layer). The fuzzified membership function is defuzzified (third hidden layer) by using Sugeno membership function to get the output neurons and lastly one output. The fuzzification, fizzy rules and defuzzification in the hidden layer are associated with the Fuzzy Inference System (FIS) in Matlab. ANFIS is actually embedded FIS in a hidden layer of ANN. 


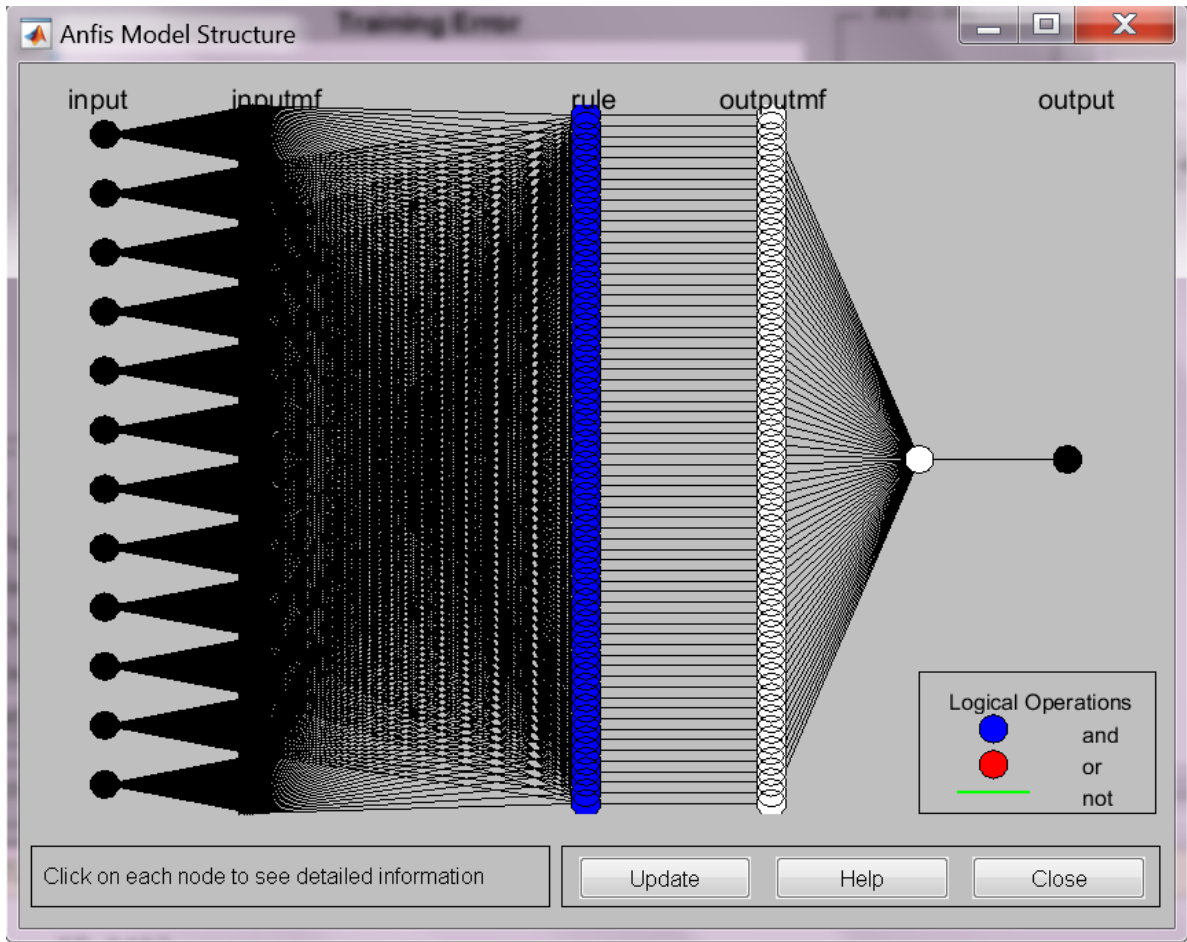

Figure 9. Structure of ANFIS

The membership function of each input can be viewed (See Figure 10) by clicking the Edit menu, membership function options. The default membership function is Gaussian.



Figure 10. Membership Function 
To view the rule of the membership function as given in Figure 11, Edit menu and Rules option are clicked.

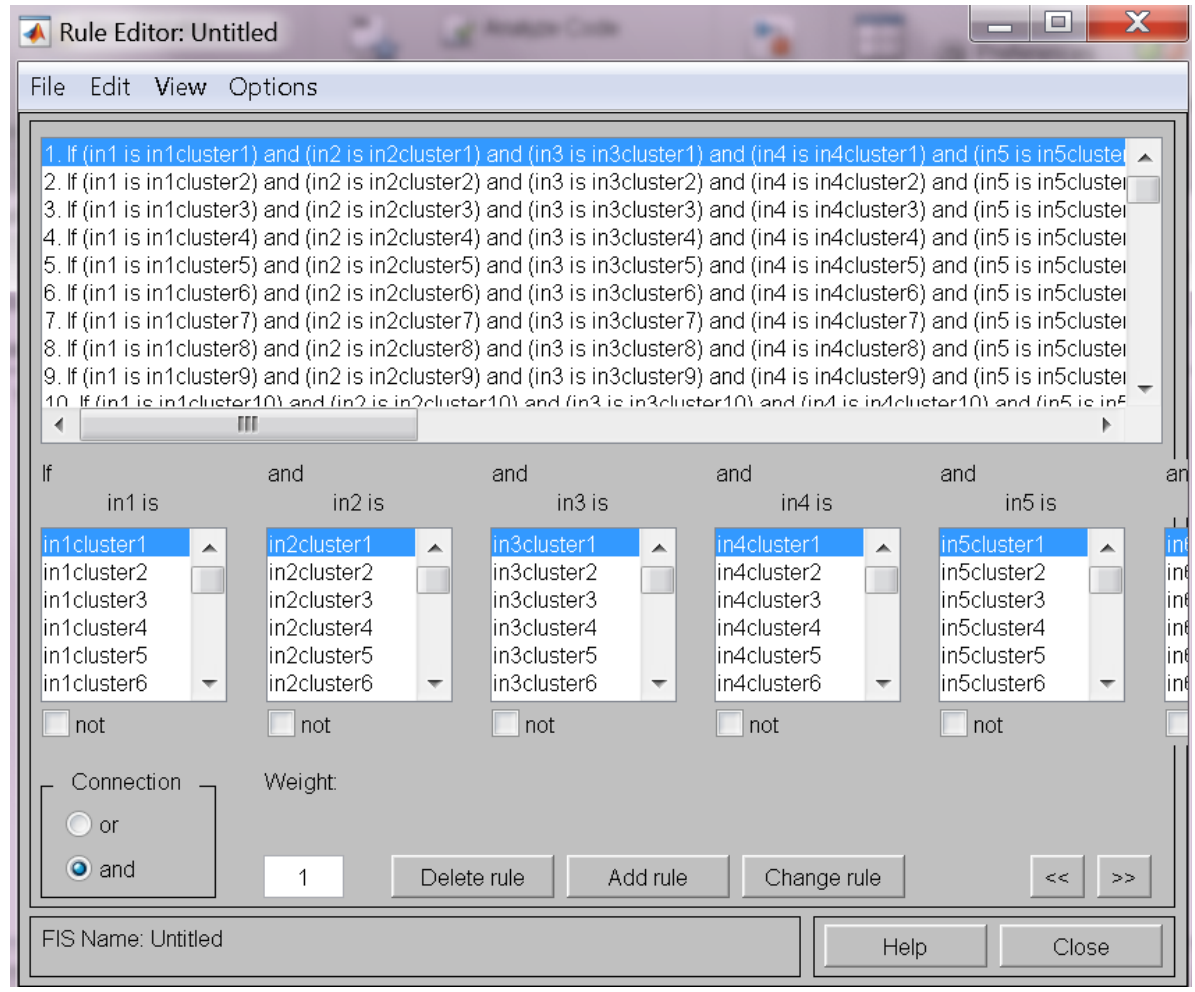

Figure 11. Membership function's rule

By clicking the View menu, Rules option, the rule for forecasting is shown as given in Figure 12. To do forecasting, copy each row of Table 1 from the first column till twelve columns and paste it on the Input box at the end of Figure 12 one by one.

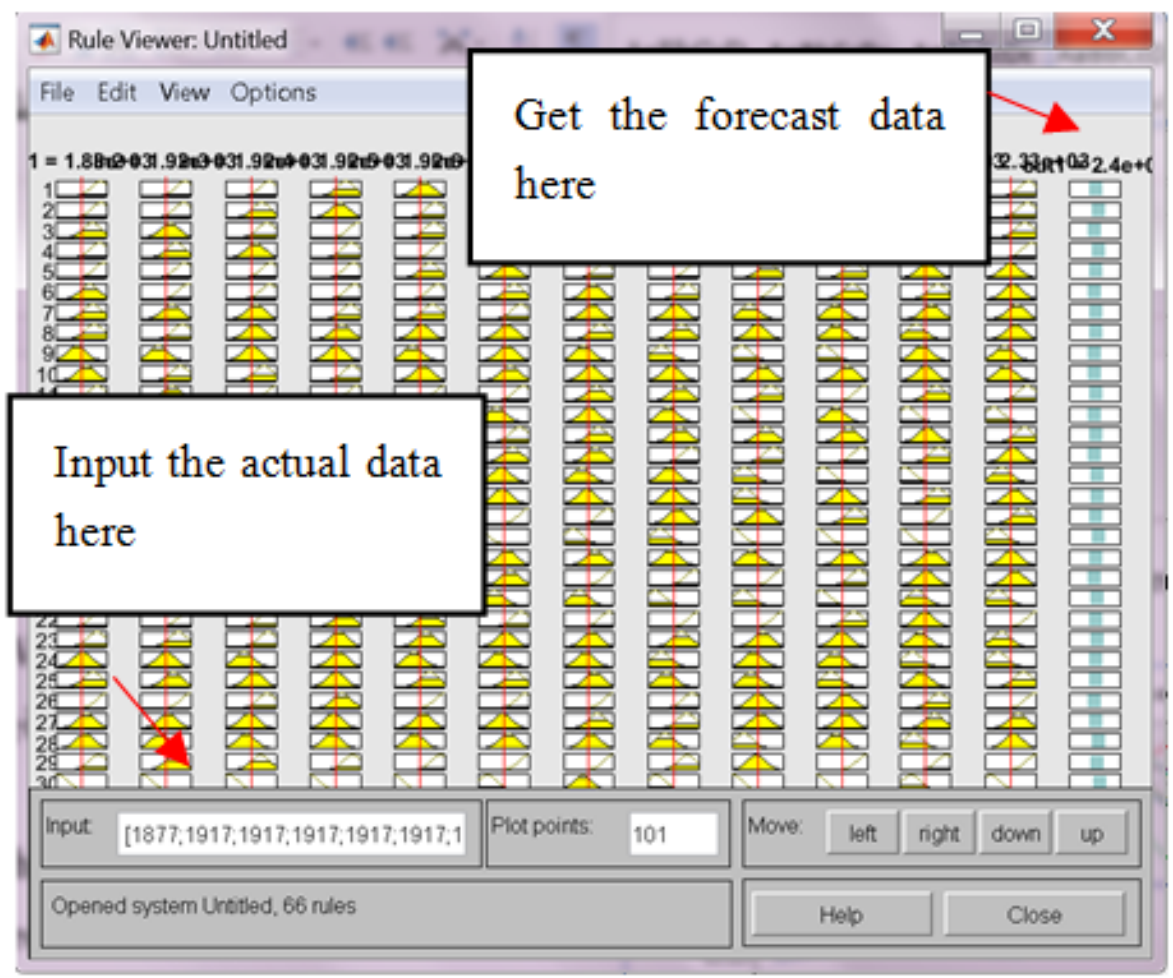

Figure 12. Rule Viewer for forecasting 
Alternatively, the forecast value can be performed faster using the following steps:

Step 1: Click File menu, Export To Workspace option and Save as Forecast as seen in Figure 13.

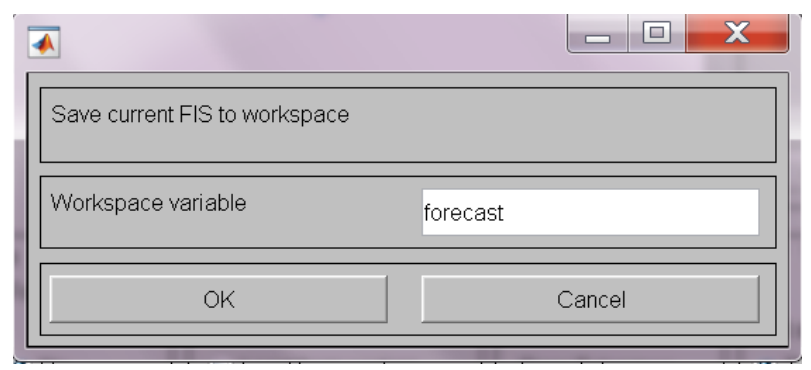

Figure 13. Forecast variable

Step 2: Type data_in $=1$ and data_out $=1$ in workspace.

Step 3: Double click data_in variable in the workspace and copy the first twelve columns of Table 1 from Excel and paste in data_in.

Step 4:Repeat Step 3 for data_out using the last column of Table 1 in Excel.

Step5: Then forecast the month 13 to month 120 by using the following command:

$\mathbf{Y}=$ evalfis(data_in, forecast).

Figure 14 shows the variables in the workspace, whereas Figure 15 gives the forecasted values from months 13 to 120.

\begin{tabular}{ll}
\hline Workspace & \\
\hline Name & Value \\
$\boxplus$ data_in & $108 \times 12$ double \\
\hline data_out & $108 \times 1$ double \\
\hline forecast & $1 \times 1$ sugfis \\
$\boxplus Y$ & $108 \times 1$ double
\end{tabular}

Figure 14. Workspace variable

\begin{tabular}{|c|c|c|c|}
\hline \multicolumn{4}{|c|}{ Editor - Annversion2018_5mar19.m } \\
\hline & data_in $x$ & data_out $x$ & $Y X$ \\
\hline \multicolumn{4}{|c|}{$\boxplus 108 \times 1$ double } \\
\hline & 1 & 2 & 3 \\
\hline 1 & $1.8015 e+03$ & & \\
\hline 2 & $1.5651 e+03$ & & \\
\hline 3 & $1.9905 e+03$ & & \\
\hline 4 & $1.8096 \mathrm{e}+03$ & & \\
\hline 5 & $1.6963 e+03$ & & \\
\hline 6 & $1.5347 e+03$ & & \\
\hline 7 & $1.9484 e+03$ & & \\
\hline 8 & $1.9500 e+03$ & & \\
\hline 9 & $1.5636 \mathrm{e}+03$ & & \\
\hline 10 & $2.1085 e+03$ & & \\
\hline 11 & $1.6351 e+03$ & & \\
\hline 12 & $1.6822 e+03$ & & \\
\hline . & $;$ & & \\
\hline
\end{tabular}

Figure 15. Forecasted values

Figure 16 indicates the blue colour (the first 12 columns) of the $108^{\text {th }}$ of data is input, while the green colour is output data (the thirteen columns) and the last column is predicted values as obtained from $Y$. To get the future forecast, we may select the $109^{\text {th }}$ row consisting of 12 columns as seen in Figure 14 to the Input box in Figure 12 or using evalfis() command to get forecasted value for month 121 . To predict for the rest of months 122-132 we may refer the data structure in Figure 16, then using Input box in Figure 12 one by one manually using Input box or can code in Matlab by using evalfis() command.

\begin{tabular}{|c|c|c|c|c|c|c|c|c|c|c|c|c|c|c|c|c|}
\hline & 12 & 108 & 2324,44 & 2117.23 & 1968.91 & 2463.97 & 2525,48 & 2235.96 & 1876.52 & 2096.15 & 1944.97 & 2164.7 & 2757.58 & 2334.59 & 2471.5 & 2471.45 \\
\hline \multirow[t]{12}{*}{2018} & 1 & 109 & 2117.23 & 1968.91 & 2463.97 & 2525.48 & 2236.96 & 1876.52 & 2096.15 & 1944.97 & 2164.7 & 2757.58 & 2334.59 & 2471.5 & & $\mathrm{~m} 121$ \\
\hline & 2 & 110 & 1968.91 & 2463.97 & 2525.48 & 2236.96 & 1876.52 & 2096.15 & 1944.97 & 2164.7 & 2757.58 & 2334.59 & 2471.5 & $\mathrm{~m} 121$ & & $\mathrm{~m} 122$ \\
\hline & 3 & 111 & 2463.97 & 2525.48 & 2236.95 & 1876.52 & 2096.15 & 1944.97 & 2164.7 & 2757.58 & 2334.59 & 2471.5 & $\mathrm{~m} 121$ & $\mathrm{~m} 122$ & & $\mathrm{~m} 123$ \\
\hline & 4 & 112 & 2525.48 & 2236.95 & 1876.52 & 2096.15 & 1944.97 & 2164.7 & 2757.58 & 2334.59 & 2471.5 & $\mathrm{~m} 121$ & $\mathrm{~m} 122$ & $\mathrm{~m} 123$ & & $\mathrm{~m} 124$ \\
\hline & 5 & 113 & 2236.95 & 1876.52 & 2096.15 & 1944.97 & 2164.7 & 2757.58 & 2334.59 & 2471.5 & $\mathrm{~m} 121$ & $\mathrm{~m} 122$ & m123 & $\mathrm{m} 124$ & & m125 \\
\hline & 5 & 114 & 1876.52 & 2096.15 & 1944.97 & 2164.7 & 2757.58 & 2334.59 & 2471.5 & $\mathrm{~m} 121$ & $\mathrm{~m} 122$ & m123 & $\mathrm{m} 124$ & m125 & & m126 \\
\hline & 7 & 115 & 2096.15 & 1944.97 & 2164.7 & 2757.58 & 2334.59 & 2471.5 & $\mathrm{~m} 121$ & $\mathrm{~m} 122$ & m123 & $\mathrm{m} 124$ & m125 & $\mathrm{m} 126$ & & $\mathrm{~m} 127$ \\
\hline & 8 & 116 & 1944.97 & 2164.7 & 2757.58 & 2334.59 & 2471.5 & $\mathrm{~m} 121$ & $\mathrm{~m} 122$ & m123 & $\mathrm{m} 124$ & m125 & m126 & $\mathrm{m} 127$ & & $\mathrm{~m} 128$ \\
\hline & 9 & 117 & 2164.7 & 2757.58 & 2334.59 & 2471.5 & $\mathrm{~m} 121$ & $\mathrm{~m} 122$ & $\mathrm{~m} 123$ & $\mathrm{~m} 124$ & m125 & m126 & $\mathrm{m} 127$ & $\mathrm{~m} 128$ & & $\mathrm{~m} 129$ \\
\hline & 10 & 118 & 2757.58 & 2334.59 & 2471.5 & $\mathrm{~m} 121$ & $\mathrm{~m} 122$ & $\mathrm{~m} 123$ & $\mathrm{~m} 124$ & m125 & m126 & $\mathrm{m} 127$ & $\mathrm{~m} 128$ & $\mathrm{~m} 129$ & & $\mathrm{~m} 130$ \\
\hline & 11 & 119 & 2334.59 & 2471.5 & $\mathrm{~m} 121$ & $\mathrm{~m} 122$ & $\mathrm{~m} 123$ & $\mathrm{~m} 124$ & m125 & m126 & $\mathrm{m} 127$ & $\mathrm{~m} 128$ & $\mathrm{~m} 129$ & $\mathrm{~m} 130$ & & m131 \\
\hline & 12 & 120 & 2471.5 & $\mathrm{~m} 121$ & $\mathrm{~m} 122$ & $\mathrm{~m} 123$ & $\mathrm{~m} 124$ & $\mathrm{~m} 125$ & $\mathrm{~m} 126$ & $\mathrm{~m} 127$ & $\mathrm{~m} 128$ & m129 & $\mathrm{m} 130$ & m131 & & m132 \\
\hline
\end{tabular}

Figure 16. Future forecast data structure 3.3. Performance 


\subsection{Performance}

The performance of the NARX was measured in terms of mean absolute percentage error as given below:

$$
M A P E=\frac{\sum_{i=1}^{n} \frac{\left|y_{i}-\hat{y}_{i}\right|}{y_{i}}}{n} \times 100 \%,
$$

where $n$ is the number of data, $y_{i}$ and $\hat{y}_{i}$ are real and predicted values correspondingly.

\section{Results and Discussions}

Figure 17 reveals UTHM monthly electricity consumption versus month by year from 2009 to 2018 . The lowest consumption is the year 2009 followed by the year 2010. The highest consumption year is 2015. The maximum consumption is 3228.53 MWh in March 2015, whereas the minimum is 496.379 MWh in January 2009. December 2014 is the highest among the month of December.

The UTHM monthly electricity consumption plotted in time sequence is shown in Figure 18. It shows the consumption time series is fluctuating and not stationary.

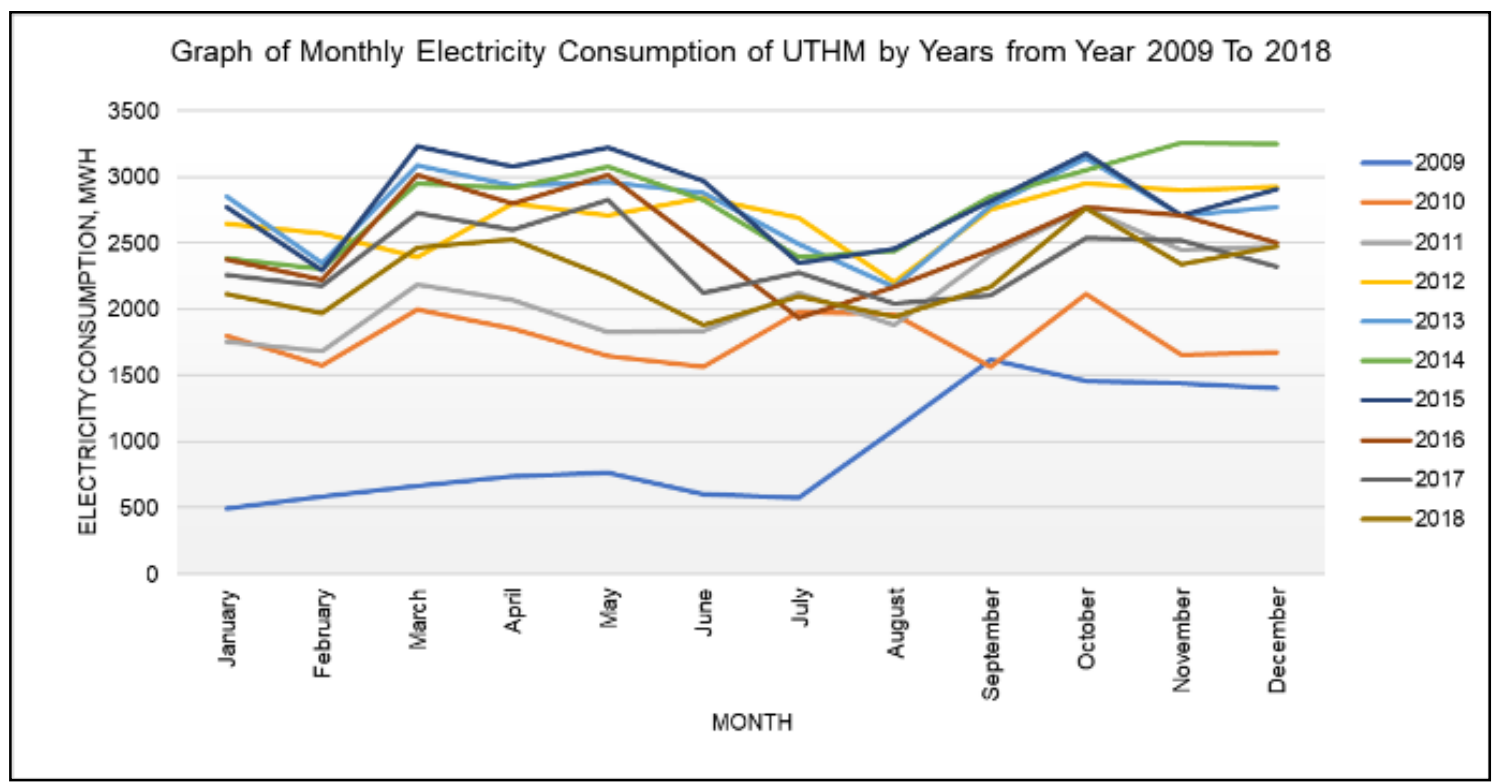

Figure 17. Monthly electricity by year

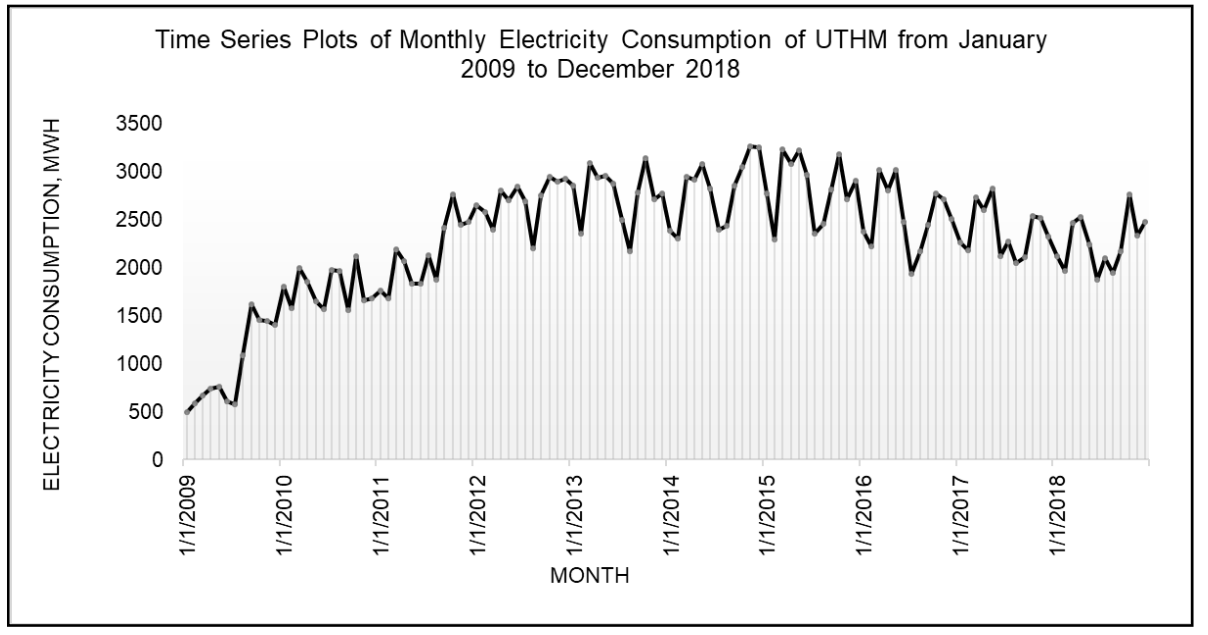

Figure 18. Monthly electricity 
The real UTHM monthly electricity consumption (month 1-120) is shown in blue colour, while predicted (month 13-132) is shown in red colour in Figure 19. It is clearly seen that most of the points are exactly overlapped.

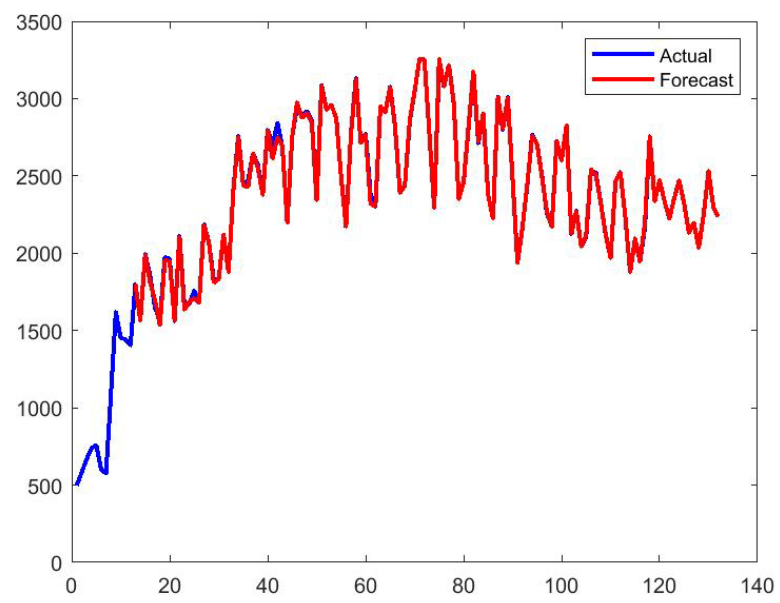

Figure 19. Monthly electricity

The year 2019 electricity consumption prediction by using ANFIS ranges from 2000 to 2530 as plotted in Figure 20. The minimum is August 2019, while the maximum is October 2019.

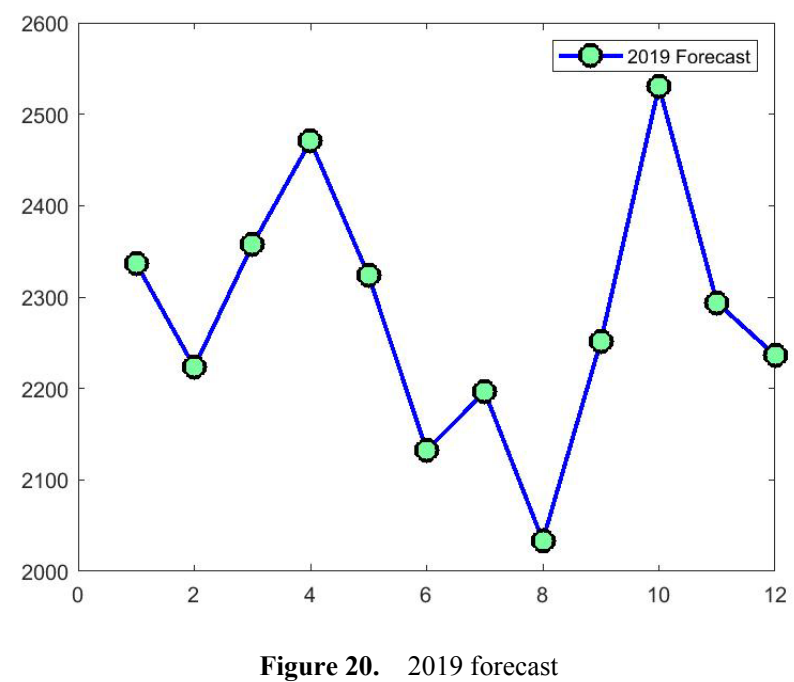

The MAPE between actual and predicted electricity consumption from month 13 to month 120 is $0.4002 \%$ which is quite small if compared to Holt-Winters [4], MLR [6] and FTS [5] which are $11.14 \%, 10.62 \%$, and $5.74 \%$ respectively. Therefore ANFIS will be introduced to the Development and Maintenance Office, UTHM as a reliable tool for forecasting.

\section{Conclusions}

Univariate monthly UTHM electricity consumption from January 2009 to December 2018 was transformed to multivariate data. This multivariate data was later inputted to ANFIS to forecast January 2009 to December 2019 electricity consumption. It is shown that ANFIS can predict electricity consumption pretty well with a small MAPE of $0.4002 \%$ if compared to [4-6].

\section{Acknowledgements}

We wish to thank Mr. Shukur Saleh and Mr. Abd Rashid Puteh from Development and Maintenance Office, UTHM for providing us with UTHM electricity consumption data, UTHM Tier 12018 research grant vote number H258 and Fundamental Research Grant Scheme (FRGS) vote K095 granted by Ministry of Education (MOE) Malaysia for financial support of this project.

\section{REFERENCES}

[1] F. Kaytez, M. C. Taplamacioglu, E. Cam \& F. Hardalac, Forecasting electricity consumption: A comparison of regression analysis, neural networks and least squares support vector machines, Electrical Power and Energy Systems, Vol. 67, 431-438, 2015.

[2] D. J. Pedregal, \& J. R. Trapero, Mid-term hourly electricity forecasting based on a multi-rate approach, Energy Conversion and Management, Vol. 51, 105-111, 2010.

[3] E. Almeshaiei, \& H. Soltan, A methodology for Electric Power Load Forecasting. Alexandria Engineering Journal, Vol. 50, 137-144, 2011

[4] Y. W. Lee, K. G. Tay \& Y. Y. Choy, Forecasting Electricity Consumption Using Time Series Model. International Journal of Engineering and Technology, Vol. 7, No. 4.30, 218-223, 2018

[5] K. G. Tay, Y. Y. Choy, \& C. Y. Chew, Forecasting Electricity Consumption Using Fuzzy Time Series. International Journal of Engineering and Technology, Vol. 7, No.4.30, 342-346, 2018.

[6] K. G. Tay, Y. Y. Choy, \& A. Huong, Forecasting Electricity Consumption Using Multiple Linear Regression. International Journal of Engineering and Technology, Vol. 7, No.4, 3515-3520, 2018.

[7] P. K. Jain, W. Quamer, \& R. Rajendra Pamula, Electricity Consumption Forecasting Using Time Series Analysis. International Conference on Advances in Computing and Data Sciences, 327-335. 2018.

[8] A.H. Erol, N. Özçelikkan, A. Tokgöz, S. Özel, S. Zaim, \& O. F. Demirey, Time Series Methods and Neural Network, 118-127, 2012.

[9] G. Ogcu, O.F Demirey \& S. Zaim, Forecasting Electricity Consumption with Neural Networks and Support Vector Regression. Procedia - Social and Behavioral Sciences, Vol. 58, 1576 - 1585, 2012. 
[10] A. Bâra, and S. V. Oprea, Electricity Consumption and Generation Forecasting with Artificial Neural Networks, Advanced Applications Artificial Neural Networks, $119-139,2017$.

[11] K. Kandananond, Forecasting Electricity Demand in Thailand with an Artificial Neural Network Approach. Energies. Vol. 4, 1246-1257, 2011.

[12] K. P. Amber, R. Ahmad, M. W. Aslam, A. Kousar, M. Usman \& M. S. Khan, Intelligent techniques for forecasting electricity consumption of buildings, Vol. 157, No.15, 886-893, 2018.

[13] M. A. Nokar, F. Tashtarian, \& M. H. Y. Moghaddam, Residential power consumption forecasting in the smart grid using ANFIS system, 7th Int. Conf. On Computer and Knowledge Engineering, 1-9, 2017.

[14] M. Mordjaoui, and B. Boudjema, Forecasting and Modelling Electricity Demand Using Anfis Predictor, Journal of Mathematics and Statistics, Vol. 7, No. 4, 275-281, 2011.

[15] S. Tiwari, V. Singh, and R. Kumar, An Intelligent System For Forecasting Electric Load And Price, International Journal of Computer Science and Information Technology. Vol. 6, No. 3, 2121-2126, 2015.

[16] S. Barak, \& S. S. Sadegh, Forecasting energy consumption using ensemble ARIMA-ANFIS hybrid algorithm, International Journal of Electrical Power and Energies, Vol. 82, 92-104, 2016

[17] J. F Chen, Q. H. Do. T. V. A. Nguyen. \& T. T. H. Doan, Forecasting Monthly Electricity Demands by Wavelet Neuro-Fuzzy System Optimized by Heuristic Algorithms, MDPI, Vol. 9, No.51, 1-26, 2018. 